Journal of Contemporary Educational Research

Research Article

\title{
Research on the Problems and Countermeasures in Cultivation of College Students' Cultural Confidence in the New Era
}

Kangjun Guo

Department of Basic Education, Southwest Petroleum University, Nanchong 637000, China

\begin{abstract}
Culture is a unique phenomenon in human society, which reflects the wisdom of human beings. It is not only the core of a country's cohesion, but also the spiritual driving force for a country to be prosperous and developed. Cultural confidence is an important theoretical content and component of $\mathrm{Xi}$ Thought on Socialism with Chinese Characteristics for a New Era, and an essential source of strength for the great rejuvenation of the Chinese nation. Under the influence of foreign cultures, college students in the new era have problems such as loss of value and lack of confidence in terms of cultural confidence. Therefore, in the course of expanding foreign exchanges and carrying out reform and opening up, it has become an important mission that cannot be delayed for the ideological and political theory teaching in colleges and universities to strengthen the cultural confidence of college students and reinforce their cultural confidence education.
\end{abstract}

Keywords: New era; Cultural confidence; College students; Ideological and political education in universities

Publication date: September, 2020

Publication online: 30 September, 2020

* Corresponding author: Kangjun Guo, 201899010066@swpu.edu.cn

Culture is the product of human practice, coheres the spiritual consciousness of a nation, and reflects its vitality and creativity. As is known to all, there are four ancient civilizations in the world, but only Chinese culture has been handed down without interruption. Since modern times, the conflict between China and the outside world has been constantly expanding in economic, political and cultural exchanges until the founding of new China and the development of reform and opening up. During this period, Chinese national culture experienced a development process from decline to recovery, and then from recovery to revival. Therefore, in today's complex, changeable and conflicted international environment, the cultivation of college students' cultural confidence must be raised to a very important position.

\section{The theoretical connotation and significance of college students' cultural confidence}

The Chinese nation has gone through more than 5,000 years of vicissitudes. In modern times, when China was carved up by foreign powers and invaded by foreign enemies, the Chinese nation still kept up fighting bravely and finally achieved national independence and the prosperity of the country, standing among the nations of the world, which is inseparable from the great and enduring Chinese culture. "When the youth prosper, the country prospers; when the youth are strong, the country becomes strong." College students are young people full of vigor and vitality, the main force to uphold cultural confidence and play a very important role in inheriting and developing the great cause of Chinese culture.

Cultural confidence of college students means that they fully affirm and approve the value and significance of Chinese culture, and have firm confidence in the powerful vitality of Chinese culture itself. First of all, if we want to have cultural confidence, we must first establish a high degree of cultural consciousness. College students should affirm and 
identify with Chinese culture on the basis of learning and understanding Chinese culture, and consciously inherit and carry forward Chinese culture, among which cultural consciousness is the necessary premise and solid foundation of cultural confidence. Second, cultural confidence is not blind confidence. When college students insist on cultural confidence, they must distinguish the essence from the dross, discard the rough and keep the fine essence, discard the false and retain the true, critically inheriting the ideology and culture. Finally, cultural confidence does not mean blind arrogance, because the world is colorful and therefore there is a diversity of cultures. College students should learn and accept the advantages and advantages of various cultures and strive to improve the shortcomings of their own culture. They should not blindly fully identify with or accept any culture. Scholar Zhao Yufei once said, "If we want to truly lead to the road of cultural self-improvement, we must affirm the value of our own culture, reasonably absorb foreign culture, and firmly believe in the tenacious vitality of our own culture $^{[1]}$."

Cultural confidence is a kind of "more fundamental, more profound and more lasting confidence", concerning the great rejuvenation of the Chinese nation, the construction of a modern power and the growth of new generation. Therefore, it is of great significance to cultivate and build cultural confidence.

Youth is the future and hope of nations. Strengthening the cultivation of college students' cultural confidence not only gets the attention of the Party and the state, but also is the objective need of the era of globalization we are facing. With the development of science and technology, human society has made continuous progress in transportation and communication technologies, and the contacts between people and countries have become closer and the exchanges have become more frequent. With the deepening of globalization, the international and domestic environment is becoming increasingly complex. Internationally, western developed countries, mainly the United States, make use of their advantages in economy, culture and network technology to export the ideology of western society to other countries and infiltrate the influence of capitalist cultural values on the youth of other countries; In China, due to the rules of the market economy and the existence of the non-public sector of the economy, individualism, hedonism, money worship and other undesirable ideological tendencies of capitalism have appeared in the society ${ }^{[2-3]}$.

In the current environment, there is a lack of cultural confidence among some college students, which is mainly reflected in the following aspects: in the face of cultural achievements from multiple countries, they lack the ability of rational judgment and choice, and are easy to accept foreign cultures and their values; At the same time, they lack a deep understanding of China's excellent traditional culture and the content of socialist core values. Cultural confidence is the source of strength to realize the great rejuvenation of the Chinese nation, and college students are cultural inheritors and innovators, so they shoulder the arduous historical task of realizing the great rejuvenation of the Chinese nation. The ideological and political education work in colleges and universities must uphold the leadership of the Communist Party of China, undertake the fundamental mission of foster virtue and educating people, and attach importance to cultivating the cultural confidence of college students ${ }^{[4]}$.

\section{Problems existing in the cultivation of college students' cultural confidence}

Colleges and universities are the main place for college students to study and live, and the battle position for cultivating their cultural confidence. Therefore, colleges and universities should fully exercise their ideological and political education functions to help college students develop a high level of cultural confidence.

To cultivate cultural confidence is to cultivate college students' confidence in the excellent traditional Chinese culture, revolutionary culture and advanced socialist culture. Only through comprehensive and complete teaching can we effectively cultivate college students' strong sense of confidence in Chinese culture. However, in the current work of cultivating college students' cultural confidence, the specific content of cultural confidence only exists in the public courses of ideology and politics, or it can only make college students understand and feel through the way of elective courses. Therefore, only by adding special courses can we enhance the pertinence and effectiveness of cultivating college students' cultural confidence.

Chinese culture has a long history and is extensive and profound. Therefore, in the process of cultivating cultural confidence, we should not only let college students learn revolutionary culture and advanced socialist culture, but also let them understand Chinese traditional culture. Only from the overall perspective 
of educational content can we effectively help college students to establish a high degree of cultural confidence. However, in the current work of cultivating college students' cultural confidence, there are few knowledge lectures related to Chinese traditional culture, and the introduction of it is only scattered in the course of Ideological and Moral Cultivation and Legal Foundation, which results in the situation that college students' understanding of Chinese traditional culture is only limited to a half-baked one. The explanation of traditional culture in the public courses and elective courses of Ideological and political education is too simple with abstract and empty contents, which ultimately leads to poor cultivation effect of cultural confidence for college students.

At present, in the process of educating college students on cultural confidence, most teachers adopt the traditional teaching method, that is, mainly by the way of infusing education, which often ignores the subject status of college students while imparting cultural knowledge. he teaching method of "what I say goes" focuses on the theoretical explanation and knowledge imparted to college students, but often neglects the importance of practical activities. Moreover, the teaching content is abstract and empty, with obvious drawbacks, unable to get close to the real life of college students, so it cannot satisfy the actual demands of college students. In this single mode of education, students become passive educatee, with a lack of interaction between the teacher on the platform and the students below. Emotional identity is an important aspect to cultivate college students' cultural confidence, and it is difficult to achieve the goal of emotional identity through single indoctrination and teaching. Learning cultural knowledge is important, but true cultural confidence must be based on emotional identity. So we should not only stress the learning and teaching of cultural knowledge, but also pay attention to the humanistic concern in the cultivation of cultural confidence. Only in this way can college students' cultural feelings and behaviors be effectively cultivated, their cultural confidence be put into practice, and finally "unity of knowledge and action" be realized.

Teachers' personal knowledge accomplishment and personality charm have a very important influence on the learning effect of college students. In the teaching process of cultivating college students' cultural confidence, some teachers have outdated and rigid teaching methods, with single teaching content, and lack of democratic and equal teacher-student relationship, which greatly reduces the teaching effect. As a result, some college students lose their interest in learning and only study for the purpose of dealing with exams. At the same time, students lose their sense of pride and identity in culture, which ultimately leads to the failure of cultivating students' cultural confidence effectively. Therefore, whether the cultural curriculum set by schools can effectively build up the cultural confidence of college students, teachers' personal accomplishment makes a big difference.

\section{Countermeasures to Improve the effectiveness of cultivating college students' cultural confidence}

Culture is an important part of a country's soft power, and the extensive, profound and glorious Chinese culture is a powerful spiritual deposit for realizing the great rejuvenation of the Chinese nation. Since entering the new era, colleges and universities across the country have rallied firmly around the CPC Central Committee with Comrade at its core, adhered to the leadership of the Party, and achieved remarkable results in fostering cultural confidence. However, while achieving excellent results, there are still some shortcomings and loopholes in the cultivation of cultural confidence in universities. For example, the curriculum setting is not scientific and reasonable, the teaching method is antiquated and conservative, and some ideological and political teachers' personal accomplishment and teaching ability are deficient. These factors lead to the insufficient effectiveness of the cultivation of college students' cultural confidence and the low degree of cultural confidence of some college students.

Classroom learning is the basic way and main channel of cultivating college students' cultural confidence, so scientific curriculum arrangement plays a decisive role in cultivating college students' cultural confidence. Therefore, according to the requirements of the CPC Central Committee and the actual needs of college students, colleges and universities should optimize the relevant curriculum in an all-round way. First, in terms of course arrangement, special courses should be added to improve the cultural confidence of college students in a targeted way. "When culture prospers, the country prospers; when culture is strong, the country becomes strong." Colleges and universities shoulder the important historical mission of cultivating the new 
generation, and the establishment of special courses of cultural confidence is the basic premise to improve the effectiveness of cultivating cultural confidence of college students. Secondly, the cultural confidence of college students should be improved in practice. Among the ideological and political courses in almost all colleges and universities, the duration of theoretical courses is generally more than that of practical courses. The advantage of this arrangement is that students can receive a large amount of knowledge and information in a short time to enrich their cultural knowledge reserve; On the other hand, abstract knowledge learning is often dull and monotonous, while the ultimate goal of theoretical learning lies in practice. Cultural confidence should not only be "internalized in the heart", but more importantly "externalized in action". Therefore, colleges and universities should not only increase the practice hours, but also put the arrangement of practice hours into practice to avoid mere formality. Thirdly, the kinds of elective courses of Chinese culture should be enriched and increased. In the long course of historical practice, the diligent and brave Chinese people have created a time-honored, extensive and profound Chinese culture. Chinese poetry, music, art, calligraphy and so on all have their unique cultural charm. By means of electives, college students can learn to understand the specific content of Chinese culture and feel the charm of Chinese culture in person, so as to avoid abstract empty talk and pure theoretical preaching ${ }^{[5-6]}$.

The development and popularization of modern communication network technology has dramatically changed people's way of production, life and learning, and Internet teaching has gradually become an important way of teaching activities, which has been widely applied especially during the COVID-19 epidemic. The communication technology innovation represented by $5 \mathrm{G}$ enables the dissemination of knowledge to break through the limitation of time and space. Even though teachers and students are thousands of miles apart, face-to-face teaching effect can be achieved. On the one hand, college students are very active molecules on the Internet; On the other hand, modern network technology can greatly enhance the dissemination, influence and appeal of Chinese culture. Therefore, in the cultivation of college students' cultural confidence, if we want to change the indoctrinationoriented education method, we must rely on network technology means to propagandize cultural knowledge to college students with intuitive and vivid videos, pictures and online course design as the teaching carrier, to improve their cultural confidence.

In the course of cultivating college students' cultural confidence, colleges and universities are the main place to cultivate, ideological and political courses are the main channel to cultivate, and teachers, as students' managers and mentors, their role is particularly important. Only with the joint efforts of government departments, universities and teachers, can teachers' personal qualities be constantly improved. First of all, according to the Party's policy on education, education authorities should give full play to their leadership role, formulate teacher training programs in a targeted way, define the development goals of teachers' personal qualities, strengthen the training of teachers' professional ethics, and advance teachers' personal qualities in an all-round way, so as to build a high-quality, professional ideological and political course teachers with a high degree of cultural selfconfidence. Second, colleges and universities should invest more money to buy educational and teaching resources on the network platform for ideological and political course teachers, enriching their classroom contents, and improve the quality of lesson preparation and teaching level of teachers by holding various forms of teaching competitions and holding regular teacher training activities. Finally, while the external objective conditions are constantly improving, individual teachers should also devote themselves whole-heartedly to the cultivation of college students' cultural confidence. In order to enhance the cultural cognition of college students, teachers should first have adequate knowledge reserve; In order to cultivate the emotional identity of college students, teachers should first develop a high level of cultural confidence. Therefore, teachers should not only increase their professional level, but also enhance their political consciousness, sense of social responsibility and professional sacredness. Through the emotional communication between teachers and students, college students are given full humanistic care. Only in a learning environment full of human kindness instead of stereotyped preaching can college students' emotional identity and cultural confidence be effectively improved.

\section{References}

[1] Zhao YF. Cultural Confidence of Chinese people, Guiyang: Confucius School Bookstore Co., Ltd., 2014, P174.

[2] Xi. Xi on governance: Volume 2 [M]. Beijing: 
Foreign Languages Press,2017:313.

[3] Shen ZH. On Cultural Confidence [M]. Wuhan: Hubei People's Publishing House,2019:91.

[4] Xi. Complete the Building of a Moderately Prosperous Society Achieve Great Success in Building Socialism with Chinese Characteristics for a New Era [M]. Beijing: People's Publishing House, 2017: 41.
[5] Cai YQ. Analysis on the Main Characteristics and Logic Theoretical Path of Cultural Confidence in the New Era [J]. Theory Guide, 2019(3): 72.

[6] Publicity Department of the CPC Central Committee. Study Outline of Xi Thought on Socialism with Chinese Characteristics for a New Era [M]. Beijing: Learning Press, 2019:40. 